ISSN 2693-2504

\title{
Urological Disorders in the Older Patient: Place of Phyto-Therapy
}

\section{Journal of Bioscience \& Biomedical Engineering}

Review Article

\begin{abstract}
Alain Bitton MD, PhD
Men's health and Andrology Clinic - 95 Route de Florissant 1206 Geneva - Swit-zerland

\author{
*Correspondence authors \\ Alain Bitton MD, PhD \\ Men's health and Andrology Clinic \\ 95 Route de Florissant \\ 1206 Geneva \\ Swit-zerland \\ www.andrologue.com
}

Submitted : 05 Jan 2021 ; Published : 15 Apr 2021

Abstract

In the era of robotic surgery, however, the quest for alternative medicine is once again a must. Herbal medicine, so decried by some, remains widely prescribed and recent and increasingly relevant studies recognize it as having a certain effec-tiveness. Indeed, natural, homeopathic and phytotherapeutic products meet a real need. Urology being a specialty which concerns more and more patients of a cer-tain age because of the longevity and the improvement of the quality of life, it is quite naturally that herbal medicine finds its place in the population of the third age that we must protect from the side effects of conventional treatments. Thus, due to ever-increasing pressure from the media as well as from patients, many doctors - including urologists - are resorting more and more frequently to the use of phyto-therapeutic substances. Especially since the imperatives of economy, which in no way spare the health sector, push professionals to prescribe effective, safe and inexpensive substances.
\end{abstract}

\section{Herbal medicine most used in urology}

\section{Plants}

Serenoa repens: This is a small palm from the Aracaceae family also called saw palmetto, Sabal or saw palm. Contained in preparations such as Per-mixon ${ }^{\circledR}$, Prostamed ${ }^{\circledR}$ or Sabcaps ${ }^{\circledR}$, it is the most common and popular herbal therapy in the treatment of Benign Prostate Hyperplasia. It mainly comprises lipids and sterols with a mixed composition and complexes of free and esterified fatty acids.

Pigeum africanum: (TADENAN $®$ ): The African plum is native to the tropi-co-equatorial regions of Africa. A mixture of lipids and sterols (phytosterols) are extracted from the bark of well-developed trees, which have anti-edematous properties and seem to act also directly on the prostate gland: stimulation of prostatic secretion, action direct to prostate cells. Phytosterols act by inhibiting cyclo- as well as lipo-oxygenase, inhibiting fibroblast proli-feration, modifying prostaglan-dins metabolism as well as inducing apopto-sis.

Squash: The part used is the seed or the pip, the main constituents of which are phytosterols. The latter have a structure very similar to dihydrotestoste-rone (DHT) involved in the regulation of prostate growth. Phytosterols also have an action on the inhibition of 5 alpha-reductase, a specific anti-inflammatory action on the tissues of the prostate, strengthen the muscles of the bladder, increase the urine flow, stabilize urination and finally protect the prostate of aging.

Hypoxis rooperi (Harzol ${ }^{\circledR} /$ Azuprostat $^{\circledR}$ ): These are extracts from plants growing in South Africa and primarily containing $\beta$-sitosterol (major active component). B-sitosterol are pow- erful inhibitors of cyclo-oxygenase as well as lipooxygenase, thus interfering with the metabolism of prosta-glandins and allowing an anti-inflammatory effect. Also production of an apoptosis inducing factor ( $\beta$-factor) inside the prostate in vitro. Nettles: Nettle extracts mainly contain hydrophilic compound of lectins, phenols and sterols. Rich in quercetin, gold-tie root relieves urination pro-blems associated with BPH and increases urine flow. It has an anti-proliferator effect on prostate cancer cells allowing even a reduction of near-ly 30 percent of their growth. Nettle is a very ubiquitous plant which deve-lops particularly well in soils rich in nitrates, its young leaves being edible, which can even constitute an industrial source of chlorophyll.

The follow-up after several years of treatment showed that the combination of se-veral plants or plant extracts was preferable to herbal medicine alone. However, scientifically, randomized double-blind studies are still too rare and not significant enough. Long-term herbal treatments are in no way dangerous. A trial treatment of 6 to 8 weeks and possibly 3 months is usually recommended. Further treatment will depend on the progress. Iterative cures every 3 to 4 months are recommended.

\section{Phytonutriments}

These are substances that have no nutritional value but have real actions on the process of carcinogenesis. These nutrients are obtained from plants, fruits and vegetables which can be combined to achieve maximum nutritio-nal effect. 
Lycopene: It is from the beta-carotene family. It is a powerful antioxidant, the effectiveness of which has already been applied in many diseases: car-diovascular, Alzheimer's, cancers, multiple sclerosis. It is recognized for its antiproliferative and preventive effects in many cancers (inverse correlation with IGF1) as well as for its "androgenic suppressor" like effect. Several con-trolled epidemiological studies report the association between the con-sumption in quantity of products containing ly-copene (tomatoes) and re-duction of the risk of mortality in many cancers. In prostate cancer, a 33 percent risk reduction was observed among patients who consumed more than 10 meals per week (30-50 mg per day). In addition, a decrease in the level of PSA is observed in patients consuming lycopene products.

Secale cereale: Pollen extracts $\left(\right.$ Cernilton $\left.^{\circledR}\right)$ : The extracts are produced by the microbial digestion of pollen plants growing in southern Sweden. The end product consists of water and soluble fatty acid fractions combined into tablets or capsules. The exact mechanism of action is unknown although there is an improvement in the activity of the destructor muscle at the bladder level, a re-duction in urethral resistance, an activity comparable to the inhibition of 5-alpha reductases. As well as an effect on intra-prostatic androgenic metabolism. Several studies show that Cernilton ${ }^{\circledR}$ significantly improves urinary symp-toms.

Green tea: Taking green tea (200 $\mathrm{mg}$ twice a day) would prevent the develop-ment of high-grade intraepithelial neoplasia (PIN) in prostate cancer (decrease in the incidence of 30 to $35 \%)$ ! The mechanism of action has been attributed to the potent effect of polyphenols. Indeed, it is observed that in 30 percent of men a high grade intraepithelial neoplasia could develop into prostate cancer. When taking tea in capsules, make sure they contain at least 18 percent polyphenols!

Soybeans: This is a cheap source of protein that has been consumed for decades in Asian countries. Regular intake of soy is recognized as respon-sible for reducing the risk of cardiovascular disease, stroke and cancer ob-served in these countries. The potential anti-carcinogenic effects of soy iso-flavones are represented by inhibition of tyrosine kinases, hormonal effects, a primary role in the stress response, antioxidant effects as well as a role in immune function. The results of several studies show that the regular con-sumption of soy milk ( $>1 \mathrm{x}$ per day) would reduce the risk of prostate cancer by 70 percent!

\section{Micronutrition}

Zinc: The prostate is an internal and external secretion gland of the genital tract. Its secretion contributes to the formation and maturation of sperm fluid. In addition, the prostate is one of the organs where Zinc is most concentrated. Numerous studies have shown a strong decrease in the Zinc concentration in a sick, inflammato-ry or cancerous prostate. It therefore seems judicious to combine this trace element with phytotherapeutic treatments. Zinc is indeed an excellent protector of the pros-tate against aging. It helps protect against free radicals by acting on the enzyme superoxide dismutase. Zinc is found in oysters ( $80 \mathrm{mg}$ per $100 \mathrm{~g}$ ), but also in pulses (lentils, beans, dry peas), oilseeds (rapeseed, soybeans, sunflower, hemp, squash and flaxseed) and eggs. . Zinc is a super antioxidant. Several studies have shown that patients with $\mathrm{BPH}$ with prostatic hardening saw their symptoms de-crease by 70 percent thanks to zinc supplementation (150 mg / day) for two mon-ths.

Selenium: A trace element essential to the human body, it plays a key role in the integrity of spermatozoa and is also one of the main players in testosterone metabolism. Intracellularly, it has an antioxidant effect, as it al-lows the body to produce glutathione peroxidase. This enzyme works toge-ther with vitamin $\mathrm{E}$ to protect cell membranes against oxidation caused by free radicals. Selenium also contributes to an essential role in the functio-ning of the immune system and the thyroid gland. Numerous epidemiologi-cal observations as well as case-control and randomized placebo-controlled studies in humans suggest that selenium decreases the risk of prostate can-cer (by up to $63 \%$ ).

\begin{tabular}{|l|l|l|}
\hline Food & Portion & $\begin{array}{l}\text { Selenium content } \\
(\mu \mathrm{g})\end{array}$ \\
\hline Brazil nut & $\begin{array}{l}14 \mathrm{~g} \text { (three to } \\
\text { four nuts) }\end{array}$ & $272 \mu \mathrm{g}$ \\
\hline Canned light tuna & $90 \mathrm{~g}$ & $63 \mu \mathrm{g}$ \\
\hline Canned sardines & $85 \mathrm{~g}$ & $45 \mu \mathrm{g}$ \\
\hline Cooked beef & $100 \mathrm{~g}$ & $36 \mu \mathrm{g}$ \\
\hline Cooked cod & $85 \mathrm{~g}$ & $32 \mu \mathrm{g}$ \\
\hline Turkey & $100 \mathrm{~g}$ & $32 \mu \mathrm{g}$ \\
\hline Egg & $1 \mathrm{medium}$ & $14 \mu \mathrm{g}$ \\
\hline Whole wheat bread & $1 \mathrm{tranche}$ & $10 \mu \mathrm{g}$ \\
\hline Cooked brown rice & $125 \mathrm{ml}$ & $10 \mu \mathrm{g}$ \\
\hline
\end{tabular}

Table 1: Food sources of selenium

Vitamins: Apart from the known beneficial effects of vitamin $\mathrm{E}$ as an antioxidant, the natural form (50 IU) would reduce the risk of prostate cancer by 40 percent in clinical studies

\section{The urological pathologies concerned}

\section{Benign prostatic hyperplasia (BPH)}

The benign dilation of the gland known as hyperplasia or prostatic hypertrophy is a benign proliferation of cells under the influence of age that occurs in more than 50 percent of men over the age of 50. As the prostate enlarges, it compresses and narrows the urethra until it stops - more or less completely - urine flow. The symp-toms linked to an obstruction of the urethra are variable and are defined as obs-tructive (low urinary pressure, impression of poorly emptying the bladder, frequent small urination, late drops, etc.) and / or irritative (urgent or urgent needs, burns, need to get up at night). In the drug treatment of BPH, the great classics are repre-sented by alpha-blockers which reduce prostate smooth muscle tone and 5-alpha-reductase inhibitors which reduce the volume of the gland. In order to reduce the significant side effects on both blood pressure and sexual function of these drugs, several phytotherapeutic sub- 
stances have been used in the treatment of BPH. These herbal medicines have a real therapeutic effect through several mechanisms of action:

- Anti-cholesterol effect: in case of BPH, the concentration of prostatic cholesterol doubles. Sisterol, for example, decreases the intestinal absorption of cholesterol

- Hormonal effect: Inhibition of 5 - alpha-reductase without decrease in prostate size or PSA value

- Effect on the bladder muscles: protective effect on the detrusor during obstruc-tion of the lower urinary tract

- Histological effect: Reduction of edema and mu-coid degeneration of the stroma and periglandular regions during BPH (Serenoa Re-pens); decrease in fibroblast growth factors (Pygeum Afri-canum)

\begin{tabular}{|l|l|}
\hline $\begin{array}{l}\text { Multifactorial clinical } \\
\text { picture of BPH }\end{array}$ & $\begin{array}{l}\text { Multifactorial action profile } \\
\text { of her-bal medicine }\end{array}$ \\
\hline $\begin{array}{l}\text { High concentration of DHT } \\
\text { in the pros-tate: binding to } \\
\text { an-drogen receptors: tissue } \\
\text { proliferation }\end{array}$ & $\begin{array}{l}\text { Anti-androgenic inhibition of 5-alpha- } \\
\text { by } \\
\text { reductase }\end{array}$ \\
\hline $\begin{array}{l}\text { Shifting of the estrogen- } \\
\text { androgen ratio in the elderly } \\
\text { patient }\end{array}$ & Anti-estrogenic effect \\
\hline $\begin{array}{l}\text { E p i th e l i u m - s t r o m a } \\
\text { interaction: prolife-ration by } \\
\text { reactivation of growth factors } \\
\text { ("embryonic awakening") }\end{array}$ & Antiproliferative effect \\
\hline $\begin{array}{l}\text { Edematous swelling and } \\
\text { associated in-flammatory } \\
\text { diseases }\end{array}$ & $\begin{array}{l}\text { Anti-edematous effect } \\
\text { Anti-inflammatory effect }\end{array}$ \\
\hline $\begin{array}{l}\text { Modification of the muscle } \\
\text { tissue-epithelium ratio in } \\
\text { favor of muscle tis-sue: } \\
\text { increased muscle tone }\end{array}$ & $\begin{array}{l}\text { Inhibition of alpha-1- } \\
\text { adrenergic re-ceptors }\end{array}$ \\
\hline
\end{tabular}

Table 2: helps to understand the importance of these different mechanisms of ac-tion in the management of BPH

\section{Prostatitis}

Although this benign prostatic disease mainly concerns young men (35-45 years old), the symptoms linked to the development of chronic prostatitis or pelvic dys-function due to prostatic hypertrophy in elderly patients can be treated. Effectively thanks to herbal preparations. It is recommended, especially in the initial phase, to combine herbal medicine with an antibiotic treatment of 2 to 4 weeks depending on the severity of the symptoms in order to maximize the anti-inflammatory ef-fects.

\section{Prostate cancer}

Prostate cancer has in recent years become the first cancer in men after 50 years. At present there is no known external risk factor. Family history certainly has a role since the risk is doubled if a first-degree relative (father, brother) has it. The risk also increases with age. The difference between the incidence of prostate cancer and the death rate indicates that in many cases the malignancy of cancer is very low, that it progresses slowly, and that patients often die with the disease rather than of this disease. Because prostate cancer can remain silent for a long time wi-thout causing any symptoms, early detection is currently recommended to increase the chances of survival. This screening includes a digital rectal examination and a blood test for PSA in all men from the age of 50 years or earlier (45 years) if there is a family history. More and more studies are highlighting the protective effects against the development of prostate cancer of certain dietary and natural subs-tances. It may be useful to remember that 70 percent of all cancers are due to healthy living, including eating disorders and diet! In the specific case of prostate cancer it would seem that the consumption of animal fats, especially red meat or cooking at high temperature would lead to the production of heterocyclic amines, potential mutagens thus increasing the risk of cancer by 2.6 times.

\section{Andropause and sexual disorders}

\section{Definition and classical treatment}

With age, men also experience behavioral changes linked to hormonal changes. The term andropause is in fact poorly chosen because humans never stop their production of androgens; so there is no "pause". The term used today is more like "age-related androgen deficiency", or DALA. These are the decrease in bioavailable testosterone; the one who builds the characters of man. Its decrease causes fatigue, sleep disorders, erectile or sexual disorders, decrease in libido, decalcification and decline in intellectual capacities ... If the symptoms described are accompanied by a drop in total testosterone less than $200 \mathrm{ng} / \mathrm{dl}$ or $8 \mathrm{mg} / 1$, then hypogonadism should be suspected. Most of the time an androgen replacement is done orally using tablets allowing an initial dosage of $160 \mathrm{mg}$. The advantage is that you can titrate and monitor testosterone levels while avoiding sudden changes in blood concentration. The downside may be that testosterone is rapidly metabolized by a first-pass effect in the liver. As a result, we will then proceed with treatments by in-jections which can be carried out every 3 to 4 weeks and, more recently, with new products more strongly dosed at 3 or 4 months. Gels or patches have certain ad-vantages such as better tolerance, are more elegant, allowing to obtain a much more physiological effect following the circadian rhythm of testosterone. The for-mal contraindications to androgen substitution remain prostate cancer and breast cancer, as well as certain metabolic disorders such as a hypercoagu-lable state. Doctors, whether generalists or specialists, should not be afraid of androgen subs-titution. If the indication is well established and the contraindications respected, an intake of testosterone will not cause prostate cancer de novo. Indeed, most patients with prostate cancer often have hypogonadism with a very low testosterone level when cancer is discovered! Rather, it appears to be the decrease in estrogen through an increase in the estradiol / testosterone ratio that is deleterious and may represent a risk factor for the development of prostate cancer. 
Does natural medicine have a place?

\section{Food}

The nutritional state is one of the essential factors to fight against the rapid installation of andropause both on the quantity of intakes $(36 \mathrm{kcal} / \mathrm{kg})$ and on the quality characterized by a diversified lipid intake rich in essential fatty acids such as long chain polyunsaturated products (arachidonic acid, eico-sapentaenic acid and docosahexanoic acid). The protein requirement is $1 \mathrm{gr}$ of protein per kilogram of body weight. The needs in micro-nutrients: richness in minerals (calcium, magnesium), selenium, zinc, vitamins A, K, or group B are important. A water intake of around 2 liters, of which a mini-mum of 0.71 in the form of drinks is essential. It is necessary to increase the consumption of nuts, hazelnuts, whole grains, legumes rich in magnesium, olive oil, soybeans, dried fruits, vegetables, fruits and limit animal fats.

\section{Healthy lifestyle}

The restoration of an ideal weight will allow regulation of aromatase and the practice of moderate and regular physical exercise will have a favorable ef-fect on both mental and physical parameters.

\section{Plants}

In any case, it is recommended to use soy, its beneficial effects being so manifold that it is inevitable; it stabilizes in particular the bone density in both sexes after 50 years. It has a hypocho-lesterolemic effect, is a precursor of nitrogen monooxide (NO) (the most powerful known vasodilator), and by its richness in arginine, a pre-cursor of NO, results in a decrease in diastolic pressure. It slows the rise of PSA in prostate cancer and even allows its prevention. In addition, it provides kidney pro-tection in diabetics and improved cognitive functions in the presence of competent intestinal bacteria.

Other anti-oxidants such as Lycopene (tomato) may be prescribed, in combination with herbs to detoxify the body. The pycnogenol extracted from grape seeds or pine bark is also a very powerful antioxidant of interest in the treatment of andro-pause. Avoidance of strict estrogenic or oxidizing products such as tobacco, or al-cohol is indicated. Adding calcium and vitamin D will counteract osteoporosis. The decrease in libido and erectile dysfunction will be usefully compensated by the use of Sabal serrulata, selenium, zinc and Vitamin B.

The use of plants that act as a precursor of essential hormones such as testoste-rone, melatonin, DHEA will in the near future make it possible to compensate for the physiological decreases and thus make it possible to delay the onset of andro-gen deficiency linked to age.

\begin{tabular}{|c|c|c|}
\hline Substance & Location & Mechanism \\
\hline Lycopene & Fruits, tomatoes & $\begin{array}{ll}\text { - } & \text { Antioxidant } \\
\text { - } & \text { Inhibition } \\
\text { l'IGF-1 }\end{array}$ \\
\hline Polyphenols & Thé & $\begin{array}{ll}\text { - } & \text { Antioxidant } \\
\text { Activation of en- } \\
\text { zymatic systems } \\
\text { - Inhibition de } \\
\text { l'EGF et TNF }\end{array}$ \\
\hline Iso-flavonoids & $\begin{array}{l}\text { Green tea } \\
\text { Soy }\end{array}$ & $\begin{array}{ll}\text { - } & \text { Antioxidant } \\
\text { - } & \text { Increase in TGF } \\
\text { Inhibition of an- } \\
\text { giogenesis }\end{array}$ \\
\hline Vitamin D & $\begin{array}{l}\text { Carrots, tomatoes, } \\
\text { fruits, UV }\end{array}$ & $\begin{array}{ll}\text { - } & \text { Cell differentiation } \\
\text { Inhibition of cell } \\
\text { growth factors } \\
\text { - Induction of apop- } \\
\text { tosis }\end{array}$ \\
\hline Vitamins E & Different seeds & $\begin{array}{ll}\text { - } & \text { Antioxidant } \\
\text { - } & \text { Action antiproli- } \\
& \text { fied-ratrice }\end{array}$ \\
\hline Selenium & Different plants & $\begin{array}{ll}\text { - } & \text { Antioxidant } \\
\text { - } & \text { Inhibition of cell } \\
\text { growth }\end{array}$ \\
\hline Zinc & Water, fruit & $\begin{array}{l}\text { Induction of apop- } \\
\text { tosis }\end{array}$ \\
\hline
\end{tabular}

Table 3: natural medicine and prevention of prostate diseases

\section{Conclusion}

Several randomized trials and some meta-analyzes suggest clinical efficacy as well as tolerability of phytotherapeutic substances. Herbal medicine has been shown to be somewhat effective, particularly in the treatment of $\mathrm{BPH}$, which is the most common pathology in aging men. The efficacy is comparable to that of alpha-blockers or 5 alpha-reductase inhibitors, which are classic treatments but have si-gnificant side effects that further aggravate the polymorbid appearance of these patients. Although the prescription of herbal medicine is considered safe and effec-tive, it is real medication and not placebos that have effects but also side effects and also drug interactions. This leads us to consider the need for prospective, ran-domized, controlled studies conducted over the long term. Nutritional supplements including selenium, lycopenes, soy and vitamin E could help prevent prostate can-cer. Before recommending such diets, it is necessary to weigh the advantages and disadvantages, to specify the optimal doses and durations of treatment and finally to know the groups in which these interventions would be the most effective (fami-lial risk of cancer of prostate for example).
Copyright: (C2021 Alain Bitton. This is an open-access article distributed under the terms of the Creative Commons Attribution License, which permits unrestricted use, distribution, and reproduction in anymedium, provided the original author and source are credited. 